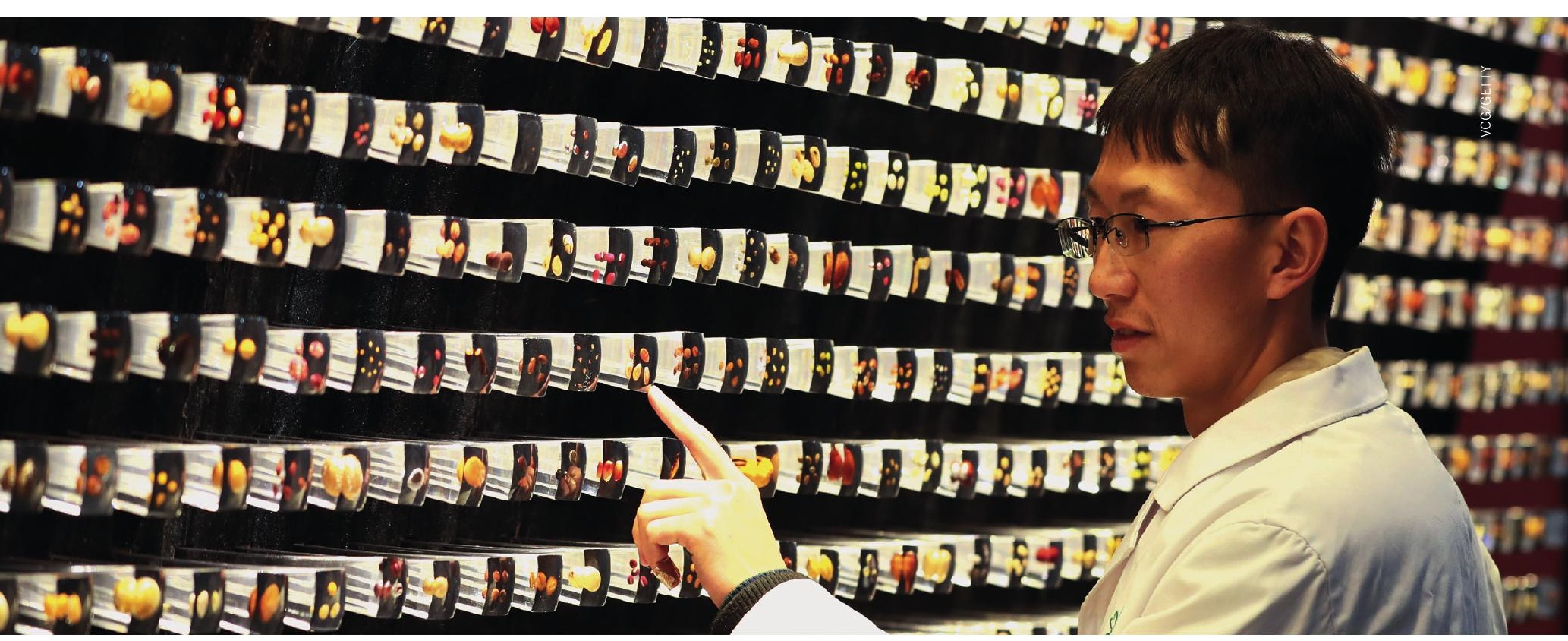

The Southwest China Germplasm Bank, established by the Kunming Institute of Botany is home to many rare plants.

\title{
A CLOSE LOOK AT CHINA'S RISE
}

A s China continues to increase its global share of research papers, it is worth remembering that publication numbers are just one indicator that a country's science is thriving.

This supplement looks beyond China's impressive performance in key metrics and examines how the country holds up in other measures of a functioning research ecosystem, such as willingness to make data and research open, science communication and sound science policy.

Until 2014, less than a fifth of China's papers in the Web of Science were co-authored with an international peer. While China still lags behind Germany, the United States and the United Kingdom in that measure, its percentage of international papers increased to $24 \%$ in 2016 . And in journals included in the Nature Index, international collaborations make up just over $50 \%$ of its papers, see Onward and upward, page S40.

Domestic collaboration remains a large contributor to China's high-quality science, driven mostly by interactions between institutions in megacities like Beijing, Shanghai and Nanjing. Intercity connections, page S44, profiles the research and collaboration of two smaller cities, whose pockets of high-quality research are at risk as the young and educated relocate to coastal cities for better opportunities.

Over the past two decades, China's scientific community has started to embrace open science, increasing its number of data repositories and open-access journals. But, strong policies and changes to academic culture are needed before science in the country can become fully open and transparent (page S62). Cultural change is also needed to boost participation in science communication among Chinese researchers (page S65).

The government's latest major science policy, known as World-Class 2.0, aims to develop, among other things, a group of globally competitive universities and first-class academic disciplines by the end of the decade, see Programmed to fulfill global ambitions, page S53. While this project aims to improve China's higher education system and reform some aspects of academic culture, it remains to be seen whether it can address systemic issues in higher education such as an over-emphasis on rankings and publishing papers in high-impact journals.

\section{Nicky Phillips}

Editor, Nature Index
EDITORIAL: Nicky Phillips, Stephen Pincock, Rebecca Dargie, Herb Brody, Richard Hodson, Vicki Kitchener, Peng Tian, Ivy Shih, Hepeng Jia, Flynn Murphy. ANALYSIS: Larissa Kogleck, Aaron Ballagh. ART \& DESIGN Alisdair Macdonald, Kate Duncan, Wojtek Urbanek, Chris Gilloch, Ruffi Lu, Chika Takeda. WEB \& DESIGN Bob Edenbach, Olivier Lechevalier, Naomi Nakahara, Pamela Sia, Bart Riepe. DATA QUALITY: Jörn Ishikawa, Yuxin Wang, Jennie Pao, Paul Glaeser. PRODUCTION: Sue Gray, Karl Smart, Ian Pope, Matt Carey, Ali Mosud, Elizabeth Campbell. MARKETING: Alan Abery. PROJECT MANAGEMENT: Anastasia Panoutsou, Rebecca Jones, Yuko Onishi. SALES: Stella Yan, Ruby Han. ART DIRECTOR: Kelly Buckheit Krause. PUBLISHING: Nick Campbell, Richard Hughes, David Swinbanks.

NATURE INDEX 2017 CHINA

Nature Index 2017 China, a supplement to Nature, is produced by Nature Research, the flagship science portfolio of Springer Nature. This publication is based on data from the Nature Index, a Nature Research website maintained and made freely available at natureindex.com.

NATURE EDITORIAL OFFICES

The Campus, 4 Crinan Street, London N1 9XW, UK

Tel: $+44(0) 2078334000$

Fax: +44 (0)20 7843 4596/7

\section{CUSTOMER SERVICES}

To advertise with the

Nature Index, please visit natureindex.com/client-services feedback@nature.com Copyright @ 2017 Macmillan Publishers Limited, part of Springer Nature. All rights reserved. 